\title{
Qualidade física e sensorial do camarão Litopenaeus vannamei cultivado em água doce
}

\author{
Physical and sensorial quality of Litopenaeus vannamei shrimp cultivated in freshwater
}

\section{Lucas de Oliveira Soares Rebouças*, Lyzandra Laís de Almeida Lemos, Danyela Carla Elias Soares, Tanyla Cybelly Lira Santos, Ana Paula Pinheiro de Assis, Maria Carla da Silva Campelo, Jean Berg Alves da Silva e Patrícia de Oliveira Lima}

Submissão: 01/02/2017 / Aceite: 23/04/2017

\section{RESUMO}

Neste trabalho, objetivou-se avaliar a qualidade do camarão marinho L. vannamei cultivado em água doce e em salgada, com ênfase nos parâmetros físicos e sensoriais. Para os parâmetros físicos foram realizadas determinações de $\mathrm{pH}$, capacidade de retenção de água (CRA), perda de peso na cocção (PPC), textura e cor (todas em triplicata). Para análise sensorial participaram do teste 30 provadores, de ambos os sexos, com idade variando entre 23 a 49 anos, para avaliar os camarões segundo os atributos de sabor, odor, cor, textura e suculência e aspecto de preferência geral. Em relação ao $\mathrm{pH}$ não houve diferença significativa $(\mathrm{p}<0,05)$ entre os dois tratamentos, assim como para CRA e PPC. Os parâmetros de cor $\left(a^{*}, b^{*}\right.$ e L*) mostraram uniformidade nos resultados, tanto para o camarão in natura como para o cozido, não havendo diferenças significativas. Destacouse a textura que apresentou diferença significativa $(p<0,05)$ entre os tratamentos, com valores de 1,03 a 1,34, corroborando com os dados reportados pela equipe sensorial. Os parâmetros sensoriais analisados não diferiram significativamente, com exceção para os atributos de odor e cor, que foram superiores para o camarão cultivado em água salgada. Apesar disso os dois tratamentos apresentaram qualidade sensorial, física e química satisfatórias.

PALAVRAS-CHAVE: carcinicultura, salinidade, qualidade de carne.

\section{ABSTRACT \\ This experiment aimed to evaluate the quality of the marine shrimp L. vannamei farmed in fresh and salt water, with emphasis on physical and \\ Universidade Federal Rural do Semiárido, Mossoró, RN, Brasil. \\ *Autor para correspondência <lucaslosr@gmail.com>}

sensory parameters. For the physical parameters $\mathrm{pH}$ determinations were performed, water holding capacity (WHC), weight loss during cooking (PPS), texture and color (all in triplicate). For sensory analysis participated in the test 30 tasters, of both sexes, aged between 23-49 years were used to assess the shrimp according to the attributes of taste, odor, color, texture and juiciness and overall preference of appearance. Regarding the $\mathrm{pH}$ there was no significant difference $(p>0.05)$ between the two treatments, as well as CRA and PPC. The color parameters $(a *, b *$ and $\mathrm{L}^{*}$ ) showed uniformity in the results for both the shrimp in nature as for the cooked, with no significant differences. The texture is highlighted where there was a significant difference $(\mathrm{p}<0.05)$ between treatments, with values from 1.03 to 1.34 , confirming the data reported by the panel. Sensory parameters analyzed did not differ significantly, except for the attributes of odor and color, which were higher for the shrimp grown in salt water. Never the less the two treatments showed sensory quality, as well as satisfactory physical and chemical quality.

KEYWORDS: shrimp farming, salinity, water quality.

\section{INTRODUÇÃO}

Os camarões estão distribuídos nos climas tropical e subtropical mundial, e são submetidos a intensa pesca nos locais onde ocorrem, o que tem causado o declínio dos estoques naturais. Por causa da pressão contínua sobre os estoques pesqueiros de camarões para consumo humano, o cultivo de camarão (carcinicultura) se desenvolveu em muitos países como uma importante ferramenta para suprir a fonte de proteína animal (LI et al. 2012). 
Esta atividade é bastante consolidada no Brasil, tendo a região nordeste como principal pólo produtor do país (POERSCH et al. 2006), destacando-se como principais produtores, os estados do Rio Grande do Norte e o Ceará, responsáveis por $95 \%$ da produção do país (ROCHA \& ROCHA 2010).

Atualmente, a espécie mais cultivada no Brasil e no mundo é Litopenaeus vannamei, que se caracteriza por ter parte do seu ciclo de vida associado aos estuários e manguezais, tolerando grande variações de salinidade, viabilizando o seu cultivo tanto em água doce como em água salgada (0-50 ppt), uma das particularidades que fazem a espécie ser considerada "rústica" (MCGRAW et al. 2002, SAMOCHA et al. 2002).

Com o desenvolvimento da carcinicultura marinha pelo mundo, enfermidades virais e a especulação imobiliária forçaram produtores a buscarem novas áreas de produção. Com o passar do tempo, novas fazendas foram surgindo cada vez mais longe das zonas litorâneas e estuarinas, até que os primeiros cultivos em água oligohalina e doce demonstraram viabilidade técnico-econômica (CAMPOS \& CAMPOS 2006).

Por ser um animal osmorregulador, o camarão marinho necessita manter constantes suas concentrações plasmáticas de sais, como o cloreto, sódio, sulfato, magnésio, cálcio e potássio. Em águas com baixas salinidades há uma tendência do animal em perder passivamente estes sais para a água, em especial via difusão branquial, o que afeta sua sobrevivência, qualidade e alguns padrões predeterminados geneticamente nesses animais, como por exemplo coloração e sabor (FIGUEIRÊDO et al. 2006).

Diversos animais inclusive os crustáceos, possuem a capacidade de alterar suas cores em função de uma série de estímulos ambientais ou por alterações endógenas (MERIGHE et al. 2004). No caso do camarão, o escurecimento da coloração da água, para uma cor com predominância de coloração marrom pode provocar o aumento da quantidade de carotenoides (principalmente Astaxantina), que irá influenciar diretamente no padrão de coloração dos camarões (OLIVEIRA et al. 2013), fazendo com que os mesmos atinjam os critérios de avaliação de coloração que são exigidos pelo mercado consumidor, e principalmente o mercado externo. No entanto, esse padrão tem sido alcançado com maior eficiência para os camarões cultivados em água salgada, apesar disso essa diferença ainda é sem caráter científico já que ainda são escassos os dados científicos que comparem a qualidade entre camarões da mesma espécie cultivados em água doce e salgada.

A qualidade do produto pode ser considerada sob o ponto de vista nutricional e por suas qualidades sensoriais. Sabe-se que a presença de certos compostos, mesmo que em pequenas quantidades, resulta em influência marcante nos aspectos sensoriais, a exemplo dos carotenoides para a cor, do colágeno para a maciez, dos ácidos graxos e outras substâncias voláteis para o aroma, sabor ou "flavour" (SOUZA et al. 2012).

Neste contexto para a avaliar os aspectos de qualidade entre o L. vannamei cultivado em água doce e salgada deve-se considerar diferentes atributos do mesmo, por exemplo o $\mathrm{pH}$, os aspectos sensoriais, os parâmetros de cor, textura, firmeza, capacidade de retenção de água, resistência ao corte e perdas na cocção. Com isso, este trabalho teve por objetivo analisar os aspectos de qualidade do camarão $L$. vannamei cultivado em água doce e salgada, com ênfase nos parâmetros físico-químicos e sensoriais.

\section{MATERIAL E MÉTODOS}

Foram utilizados dois grupos amostrais, um representado por animais cultivados em ambiente de água doce $(0 \mathrm{ppm})$ sendo identificados como "AD" e outro representado por animais cultivados em ambiente de água salgada (45 ppm) identificados por "AS". Foram utilizadas amostras de camarão branco inteiro (Litopenaeus vannamei) provenientes de cultivo comercial da cidade de Mossoró, RN.

Logo após a despesca, as amostras, com cerca de $1 \mathrm{~kg}$ de camarão, foram acondicionadas em caixas isotérmicas com gelo (proporção 1:1) e transportadas ao Laboratório de Análises Instrumentais e Sensoriais (LANIS) da Universidade Federal Rural do Semiárido. O tempo decorrido entre a despesca e chegada ao laboratório não ultrapassou $24 \mathrm{~h}$. As amostras foram preparadas imediatamente após sua chegada ao laboratório, sendo submetidas ao processamento mínimo, com as operações de retirada de cabeça e casca, e lavagem superficial, em seguida, foram devidamente identificados e armazenados em refrigerador $\left(5^{\circ} \mathrm{C}\right)$ para posteriores análises.

Para a análise sensorial, as amostras foram envoltas em papel alumínio e cozidas em água em ebulição até atingirem temperatura interna de $72{ }^{\circ} \mathrm{C}$ 
(5 minutos), servidas em copos plásticos de $50 \mathrm{ml} \mathrm{a}$ $35{ }^{\circ} \mathrm{C}$, devidamente codificados com números aleatórios de três dígitos (MEILGAARD et al. 1999).

Participaram do teste 30 provadores não treinados, de ambos os sexos, com idade variando entre 23 a 49 anos. Cada ficha de avaliação continha seis escalas estruturadas de nove pontos, variando entre zero e nove, para os registros dos julgamentos em relação ao odor, cor, sabor, suculência, textura e preferência geral sendo zero referente a nota que menos gostou e nove a que mais gostou.

Para avaliar a qualidade física das amostras foi determinado o potencial hidrogeniônico $(\mathrm{pH})$, capacidade de retenção de água (CRA), perda de peso por cocção (PPC) do camarão fresco e após a cocção foi verificado a força de cisalhamento $\left(\mathrm{Kgf} / \mathrm{cm}^{2}\right)$ e os parâmetros objetivos de cor ( $\left.\mathrm{L}^{*}, \mathrm{a}^{*} \mathrm{e} \mathrm{b}\right)$.

$\mathrm{O} \mathrm{pH}$ das amostras foi determinado através de pHmetro digital (HANNA ${ }^{\circledR}$ modelo HI 99163), acoplado a um eletrodo de penetração, previamente calibrado.

A capacidade de retenção de água (CRA) foi determinada segundo a técnica de HAMM (1960), pelo método de pressão com papel-filtro e também calculada segundo a metodologia adaptada de OSÓRIO et al. (1998), que pesa-se a amostra inicial e a amostra final, e por diferença, calcula a quantidade de água perdida. Os resultados foram obtidos por diferença entre os pesos das amostras, antes e depois de ser submetida à pressão de $5 \mathrm{~kg}$, durante cinco minutos.

As perdas de peso durante a cocção (PPC) foram calculadas pela diferença de peso das amostras antes e depois da cocção e expressas em porcentagem (WARRIS 2003). As amostras de camarão foram envolvidas em papel alumínio e grelhadas até atingir $70{ }^{\circ} \mathrm{C}$ de temperatura interna.

A cor foi determinada em colorímetro Konica Minolta, CM-700d/600d (Sistema CIE L*a*b*), cujo sistema considera as coordenadas $\mathrm{L}^{*}$ luminosidade (preto/branco), a* teor de vermelho (verde/vermelho) e b* teor de amarelo (azul/amarelo) (ZHANG et al. 2015).

As amostras usadas para PPC foram também utilizadas para a análise da força de cisalhamento (FC), através do texturômetro. A força de cisalhamento foi registrada em texturômetro (TEXTURE ANALYZER TA-XT-125) acoplado ao dispositivo Warner-Bratzler (HDP/WBV) (QUEIROGA et al. 2014), os resultados foram expressos em kg-f (quilograma força), obtidos pelas médias de força máxima de ruptura das amostras.

Para verificar a qualidade microbiológica do produto a ser ofertado nos testes foram realizadas análises microbiológicas utilizando a metodologia proposta pela Instrução Normativa 62/2003 do Ministério da Agricultura, Pecuária e Abastecimento (BRASIL 2003) para identificar a presença de Staphylococcus spp., Coliformes a $35{ }^{\circ} \mathrm{C}$ e $45{ }^{\circ} \mathrm{C}$ e Salmonella sp. Os resultados das análises microbiológicas foram expressos em UFC/g para Staphylococcus spp. e em NMP/g para Coliformes a $35^{\circ} \mathrm{C}$ e $45^{\circ} \mathrm{C}$.

Os dados das análises físicas e sensoriais foram submetidos à análise de variância (ANOVA) e as médias foram comparadas pelo teste de $\mathrm{t}$ Student ao nível de 5\% de significância, com o auxílio do programa SISVAR versão 5.6.

\section{RESULTADOS E DISCUSSÃO}

Os perfis sensoriais para os camarões analisados, estão representados graficamente na Figura 1, onde não foi observado diferença $(\mathrm{p}>0,05)$ nos atributos sabor, textura e suculência. Já para os atributos odor e cor, as amostras de camarão cultivado em água salgada apresentaram maiores médias diferindo estatisticamente das amostras de camarão cultivado em água doce (Tabela 1).

Segundo SOUZA et al. (2012), os organismos aquáticos são suscetíveis à absorção de substâncias químicas presentes no ambiente de cultivo, como a geosmina e 2-Metilisoborneol que são resultantes da alta taxa de decomposição algal, sendo responsáveis, respectivamente, pelo cheiro de terra e bolor ou mofo na água. Ainda, segundo os mesmos autores o pescado cultivado em água doce é mais suscetível à absorção dessas substâncias por possuírem maior permeabilidade através das brânquias. Tal fato pode estar associado às menores notas obtidas nos atributos odor e cor pelas amostras de camarão cultivado em água doce.

O teste de preferência demonstrou que $83 \%$ dos provadores preferiram o camarão cultivado em água salgada, enquanto $17 \%$ preferiram o camarão cultivado em água doce (Figura 2). Essa diferença entre a aceitação dos camarões pelos julgadores está relacionada com preferências pessoais e diferentes percepções, pois nenhum provador conhecia os produtos previamente, nem sabiam quais seriam os tratamentos aplicados durante a análise sensorial. 


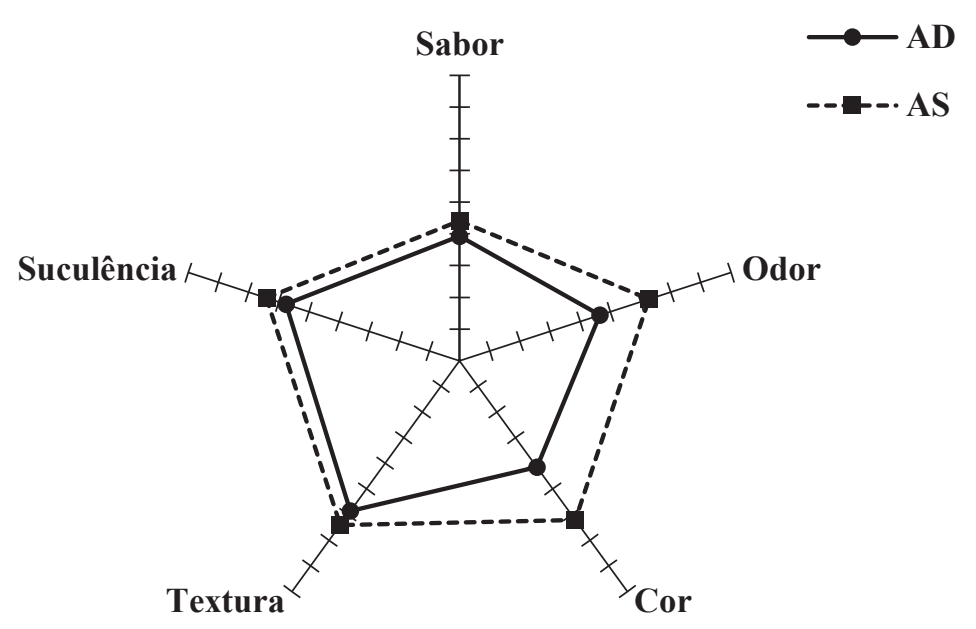

Figura 1. Perfil sensorial descritivo dos camarões cultivados em água doce e em água salgada.

Figure 1. Sensory descriptive profile of freshwater and saltwater prawns.

Tabela 1. Características sensoriais dos camarões cultivados em água doce e água salgada obtidas através da análise descritiva quantitativa (ADQ).

Table 1. Sensorial characteristics of shrimp cultivated in freshwater and salt water obtained through quantitative descriptive analysis $(A D Q)$.

\begin{tabular}{lcc}
\hline Descritores Sensoriais & AD & AS \\
\hline Sabor & $3,93 \pm 1,99^{\mathrm{a}}$ & $4,41 \pm 2,30^{\mathrm{a}}$ \\
Odor & $4,65 \pm 2,45^{\mathrm{b}}$ & $6,28 \pm 2,61^{\mathrm{a}}$ \\
Cor & $4,14 \pm 2,15^{\mathrm{b}}$ & $6,21 \pm 1,70^{\mathrm{a}}$ \\
Textura & $5,86 \pm 2,01^{\mathrm{a}}$ & $6,41 \pm 1,66^{\mathrm{a}}$ \\
Suculência & $5,76 \pm 2,08^{\mathrm{a}}$ & $6,41 \pm 1,66^{\mathrm{a}}$ \\
\hline
\end{tabular}

a,b Valores seguidos de mesma letra nas linhas não diferem significativamente pelo teste $t$ de Student $(p>0,05)$, (média $\pm \mathrm{DP}, \mathrm{n}=30$ ). AD: água doce, $\mathrm{AS}$ : água salgada.

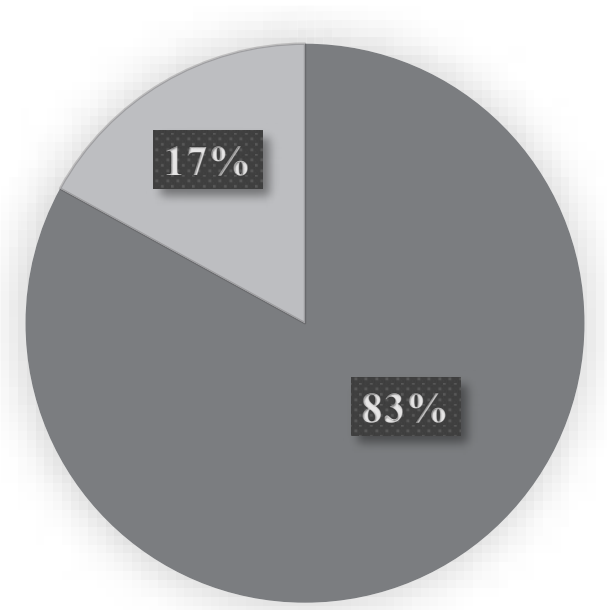

—ÁGUA SALGADA

$\square$ ÁGUA DOCE

Figura 2. Preferência dos provadores para as amostras testadas.

Figure 2. Preference of the tasters for the tested samples. 
Segundo MADRID (2011), o principal parâmetro relacionado ao sabor dos crustáceos é a salinidade da água de cultivo. De acordo com o autor, as espécies cultivadas em ambientes de água doce têm menos "sabor a pescado" que as cultivadas em água salgada, pois a pressão osmótica é menor nas espécies de água doce. Existindo assim menores quantidades de compostos intracelulares responsáveis pelo sabor.

Na Tabela 2 são apresentados os resultados das análises físicas realizadas nas amostras de camarão cultivado em água doce e salgada. Os valores relativos às análises de $\mathrm{pH}$ não apresentaram diferença significativa $(\mathrm{p}>0,05)$ entre os dois tratamentos analisados. Apresentando valores médios de $\mathrm{pH}$ dentro dos limites considerados aceitáveis para pescado fresco, segundo a legislação vigente no território nacional - RIISPOA (BRASIL 1952), que estabelece uma faixa de $\mathrm{pH}$, variando de 6,5 a 6,8 para a carne (músculo) de pescado fresco. Desse modo, os valores obtidos indicam que não ocorreram processos deteriorativos, os quais normalmente elevam o $\mathrm{pH}$, em função do acúmulo de bases voláteis produzidas pela atividade microbiana, sendo assim, quanto maior o valor do $\mathrm{pH}$ maior a atividade bacteriana (JAY 2005, TAVARES \& GONÇALVES 2011).

No aspecto colorimétrico, os valores de intensidade de cor vermelha $\left(\mathrm{a}^{*}\right)$ e de amarelo $\left(b^{*}\right)$ das amostras diferiram $(p<0,05)$, no qual o camarão cultivado em água salgada apresentou menor intensidade da cor vermelha e amarela. Já na luminosidade $\left(\mathrm{L}^{*}\right)$ não houve diferença entre as amostras. Após a cocção, houve um acréscimo em todos os parâmetros de cor, porém os tratamentos não diferiram. Segundo CIANCI et al. (2002) diferenças de coloração entre camarões frescos e cozidos são devido ao efeito batocrômico que é responsável por quebrar a astaxantina, que é a proteína presente no camarão fresco, a astaxantina livre absorve a luz a 470-472 nm (amarelo, laranja e tons de vermelho). Uma vez que este composto se liga a proteína, existe uma mudança no comprimento de onda de $580 \mathrm{~nm}$ (verde, azul ou púrpura).

A capacidade de retenção de água (CRA) não apresentou diferença $(p>0,05)$ entre os tratamentos analisados, e as amostras possuíram em média $60 \%$ de capacidade de reter água, corroborando com os valores encontrados por QUEIROGA et al. (2014). Os altos valores de CRA representam que a perda de peso é reduzida, indicando manutenção da palatibilidade e valor nutricional da amostra (GUERRA 2010), neste sentido, a CRA tem forte importância no desenvolvimento e na apreciação das características sensoriais, no valor nutritivo, no valor comercial e na atitude tecnológica da carne (ORDÓÑEZ et al. 2005).

Os valores referentes à perda de peso no cozimento (PPC) também não apresentaram diferenças $(\mathrm{p}>0,05)$ entre os tratamentos de água doce e salgada, com 42,55 e 39,88, respectivamente. A perda de peso no cozimento é uma importante característica de qualidade, associada ao rendimento da carne no momento do consumo (PARDI et al. 1993), sendo influenciada pela capacidade de retenção de água nas estruturas da carne (BOUTON et al. 1971). Além das características de qualidade, as perdas por cocção também influenciam a cor, a força de cisalhamento e a suculência da carne (BONAGURIO 2001).

Em relação à textura houve diferença $(\mathrm{p}<0,05)$ entre as amostras, a força de cisalhamento foi maior para o camarão cultivado em água salgada. De acordo com KUBITZA (1999), diversas características das carnes do pescado cultivado, como o teor da gordura, a coloração e a textura, podem ser significativamente influenciadas pela composição das rações e pelo manejo alimentar.

A qualidade dos camarões ofertados na análise sensorial é de grande relevância. Para tanto, foi realizado uma análise microbiológica prévia nas amostras para garantir a segurança dos provadores. Os resultados das análises do camarão in natura nos dois tratamentos encontram-se na Tabela 3.

Os padrões microbiológicos sanitários de alimentos são regulados pela Agência Nacional de Vigilância Sanitária (ANVISA) na Resolução RDC $\mathrm{N}^{\circ} 12$ de 2 de janeiro de 2012. Observou-se que todas as amostras analisadas estiveram dentro dos limites propostos pela legislação vigente para pescado fresco. No que diz respeito às análises de coliformes termotolerantes a 35 e $45^{\circ} \mathrm{C}$, foram observados valores iguais $(<3)$ para todas as amostras, que é inferior ao valor estabelecido pela legislação brasileira (BRASIL 2001). Não foi encontrado Staphylococcus spp. em nenhuma amostra analisada, a ANVISA, estabelece padrão microbiológico para Staphylococcus spp. em camarões da ordem de 5,0 x $10^{2} \mathrm{UFC} / \mathrm{g}$ (BRASIL 2001). A Salmonella sp. esteve ausente em todas as todas as amostras, conforme estabelecido pela Anvisa que estabelece a ausência de Salmonella sp. a cada 25 $\mathrm{g}$ de produto como requisito de segurança alimentar para os crustáceos (BRASIL 2001). 
Tabela 2. Caracterização física e química para Litopenaeus vannamei cultivado em água doce e salgada. Table 2. Physical and chemical characterization for Litopenaeus vannamei grown in fresh and salt water.

\begin{tabular}{lcc}
\hline Análises & AD & AS \\
\hline $\mathrm{pH}$ & $6,35 \pm 0,05^{\mathrm{a}}$ & $6,59 \pm 0,25^{\mathrm{a}}$ \\
Fresco & & \\
$\mathrm{a}^{*}$ & $0,24 \pm 0,26^{\mathrm{a}}$ & $-0,91 \pm 0,45^{\mathrm{b}}$ \\
$\mathrm{b}^{*}$ & $1,29 \pm 0,39^{\mathrm{a}}$ & $-0,58 \pm 0,78^{\mathrm{b}}$ \\
$\mathrm{L}^{*}$ & $37,69 \pm 3,64^{\mathrm{a}}$ & $41,28 \pm 5,56^{\mathrm{a}}$ \\
Após a cocção & & \\
$\mathrm{a}^{*}$ & $18,78 \pm 6,17^{\mathrm{a}}$ & $11,47 \pm 2,12^{\mathrm{a}}$ \\
$\mathrm{b}^{*}$ & $6,35 \pm 0,05^{\mathrm{a}}$ & $6,59 \pm 0,25^{\mathrm{a}}$ \\
L* $^{*}$ & $59,72 \pm 10,87^{\mathrm{a}}$ & $60,42 \pm 14,98^{\mathrm{a}}$ \\
CRA (\%) & $58,67 \pm 8,08^{\mathrm{a}}$ & $61,00 \pm 5,12^{\mathrm{a}}$ \\
PPC (\%) & $42,55 \pm 1,60^{\mathrm{a}}$ & $39,88 \pm 4,91^{\mathrm{a}}$ \\
Textura & $1,03 \pm 0,09^{\mathrm{a}}$ & $1,34 \pm 0,10^{\mathrm{b}}$ \\
(Kgf) & & \\
a,bValores seguidos de mesma letra nas linhas não diferem (p>0,05) pelo teste t de Student (média $\pm D P, \mathrm{n}^{\mathrm{a}}$ ). AD: \\
água doce, AS: água salgada, CRA: capacidade de retenção de água, PPC: peso pós cocção.
\end{tabular}

Tabela 3. Análise microbiológica do Litopenaeus vannamei cultivado em água doce e salgada. Table 3. Microbiological analysis of Litopenaeus vannamei grown in fresh and salt water.

\begin{tabular}{ccccc}
\hline Amostra & $\begin{array}{c}\text { Coliformes à } 35^{\circ} \mathrm{C} \\
(\mathrm{NMP} / \mathrm{g})\end{array}$ & $\begin{array}{c}\text { Coliformes à } 45^{\circ} \mathrm{C} \\
(\mathrm{NMP} / \mathrm{g})\end{array}$ & $\begin{array}{c}\text { Staphylococcus spp. } \\
(\mathrm{UFC} / \mathrm{g})\end{array}$ & Salmonella $\mathrm{sp.}$ \\
\hline $\mathrm{AD}$ & $<3$ & $<3$ & $<1,0 \times 10^{1}$ & AUSENTE \\
$\mathrm{AS}$ & $<3$ & $<3$ & $<1,0 \times 10^{1}$ & AUSENTE \\
\hline
\end{tabular}

$\mathrm{NMP} / \mathrm{g}$ - número mais provável; UFC/g - unidades formadoras de colônias/g. AD: água doce, AS: água salgada.

Deste modo, os resultados evidenciaram a manipulação adequada na captura, processamento e exposição em condições adversas quanto ao tempo/ temperatura e a qualidade das amostras de camarão que posteriormente foram servidas na análise sensorial.

\section{CONCLUSÕES}

Apesar da maior preferência dos avaliadores pelo camarão cultivado em água salgada, o camarão cultivado em água doce foi semelhante nos principais atributos sensoriais, como sabor, textura e suculência. Em relação aos parâmetros físicos de qualidade ambas amostras apresentaram bons índices. Assim, o cultivo da espécie marinha Litopenaeus vannamei em água doce desponta como uma alternativa, possibilitando a utilização de áreas mais distantes do litoral para a prática da atividade, mantendo a qualidade da matéria prima.

\section{REFERÊNCIAS}

BONAGURIO S. 2001. Qualidade da carne de cordeiros Santa Inês puros e mestiços com Texel abatidos com diferentes pesos. Dissertação (Mestrado em Zootecnia) Lavras: UFLA. 150p.

BOUTON PE et al. 1971. Effects of ultimate $\mathrm{pH}$ upon the waterholding capacity and tenderness of mutton. Journal of Food Science 36: 435-439.

BRASIL. 1952. Ministério da Agricultura, Pecuária e Abastecimento (MAPA). Aprova o novo Regulamento de Inspeção Industrial e Sanitária de Produtos de Origem Animal - RIISPOA. Decreto ${ }^{\circ} 30.691$, de 29 de março de 1952. Diário Oficial da União, Brasília, DF, 7 de julho 
de 1952.

BRASIL. 2001. Ministério da Saúde. Resolução RDC $\mathrm{n}^{\mathrm{o}}$ 12, de 02 de janeiro de 2001. Aprova o Regulamento Técnico sobre Padrões Microbiológicos para Alimentos. Diário Oficial da República Federativa do Brasil. Brasília, DF. Seção 1, nº7-E. p.45-53. 10 jan. 2001.

BRASIL. 2003. Ministério da Agricultura, Pecuária e Abastecimento. Instrução Normativa ${ }^{\circ} 62$ de 26 de agosto de 2003. Oficializa os Métodos Analíticos Oficiais para Análises Microbiológicas para Controle de Produtos de Origem Animal e Água. Diário Oficial da União, BrasíliaDF.

CAMPOS KC \& CAMPOS RT. 2006. Alternativa econômica para o novo rural do Nordeste brasileiro: o cultivo do camarão Litopenaeus vannamei em água doce. Revista Informe GEPEC 10: 40-53.

CIANCI M et al. 2002. The molecular basis of the coloration mechanism in lobster shell: $\beta$-Crustacyanin at 3.2- $\AA$ resolution. Proceedings of the National Academy of Sciences 99: 9795-9800.

FIGUEIRÊDO MCB et al. 2006. Impactos ambientais da carcinicultura de águas interiores. Engenharia Sanitária e Ambiental 11: 231-240.

GUERRA ICD. 2010. Efeito do teor de gordura na elaboração de mortadela utilizando carne de caprinos e de ovinos de descarte. 2010. Dissertação (Mestrado em Ciência e Tecnologia de Alimentos). João Pessoa: UFPB. 88p.

HAMM R. 1960. Biochemistry of meat hydratation. Advances in Food Research 10: 355-463.

JAY JM. 2005. Microbiologia de alimentos. 6.ed. Porto Alegre: Artmed. 712p.

KUBITZA F. 1999. "Off-flavor”, Nutrição, Manejo Alimentar e Manuseio Pré-Abate afetam a Qualidade do Peixe Destinado à Mesa. Revista Panorama da Aquicultura 54: 39-49.

LI MH et al. 2012. Evaluation of corn gluten feed and cottonseed meal as partial replacements for soybean meal and corn in diets for pond-raised hybrid catfish, Ictalurus punctatus x I. furcatus. Journal of the World Aquaculture Society 43: 107-113.

MADRID RM. 2011. ¿Se puede modificar el sabor del pescado? Infopesca Internacional 48: 19-24.

McGRAW KJ et al. 2002. Different colors reveal different information: how nutritional stress affects the expression of melanin-and structurally based ornamental plumage. Journal of Experimental Biology 205: 3747-3755.

MEILGAARD $M$ et al. 1999. Sensory evaluation techniques. 3.ed. Boca Raton: CRC Press. 416p.

MERIGHE GKF et al. 2004. Efeito da Cor do Ambiente sobre o Estresse Social em Tilápias do Nilo (Oreochromis niloticus). Revista Brasileira de Zootecnia 33: 828-837.

OLIVEIRA DD et al. 2013. Recuperação de carotenoides pela hidrólise enzimática proteica dos resíduos de camarão. In: Simpósio Latino Americano de Ciências de Alimentos
- 10 SLACA. Anais.... Campinas - FEA/UNICAMP. (Pôster).

ORDÓÑEZ JA et al. 2005. Tecnologia de alimentos: alimentos de origem animal. v.2. Porto Alegre: Artmed. 280p.

OSÓRIO JC et al. 1998. Métodos para avaliação da produção da carne ovina: in vivo, na carcaça e na carne. Pelotas: Editora Universitária. 107p.

PARDI MC et al. 1993. Ciência, higiene e tecnologia da carne: tecnologia da sua obtenção e transformação. Goiânia: CEGRAF-UFG. 586p.

POERSCH L et al. 2006. Perspectivas para o desenvolvimento dos cultivos de camarões marinhos no estuário da Lagoa dos Patos, RS. Ciência Rural 36: $1337-$ 1343.

QUEIROGA IMBN et al. 2014. Qualidade sensorial do camarão Litopenaeus vannamei congelado. Semina: Ciências Agrárias 35: 1801-1812.

ROCHA IP \& ROCHA DM. 2010. Análise da produção e do mercado interno e externo do camarão cultivado. Revista da ABCC 1: 18-23.

SAMOCHA TM et al. 2002. Review of some recent developments in sustainable shrimp farming practices in Texas, Arizona, and Florida. Journal of Applied Aquaculture 12: 1-42.

SOUZA SMG et al. 2012. Off-flavor por geosmina e 2-Metilisoborneol na aquicultura. Semina: Ciências Agrárias 33: 835-846.

TAVARES M \& GONÇALVES AA. 2011. Aspectos Físico-Químicos do Pescado. In: GONÇALVES AA. (Ed.). Tecnologia do pescado: ciência, tecnologia, inovação e legislação. São Paulo: Editora Atheneu. p. 10-20.

WARRIS PD. 2003. Ciencia de la carne. Zaragoza: Acribia. $320 \mathrm{p}$.

ZHANG B et al. 2015. Shelf-life of pacific white shrimp (Litopenaeus vannamei) as affected by weakly acidic electrolyzed water ice-glazing and modified atmosphere packaging. Food Control 51: 114-121. 